\title{
Mid-term Results of Single-Radius Cruciate Retaining Total Knee Arthroplasty: Minimum 5 Year Follow-up
}

\author{
Kwang Mee Kim, $\mathrm{PhD}^{1}$, Keun Churl Chun, $\mathrm{MD}^{2}$, Jae Sun Hwang, $\mathrm{MD}^{2}$, and Churl Hong Chun, $\mathrm{MD}^{2}$ \\ ${ }^{1}$ Department of Nursing School, Chodang University, Muan; ${ }^{2}$ Department of Orthopedic Surgery, Wonkwang University School of Medicine \& Hospital, Iksan, Korea
}

\begin{abstract}
Purpose: The single-radius design of the knee implant was introduced to improve the results of total knee arthroplasty (TKA) by reducing maximum extensor forces, and it also represents more physiologic quadriceps force pattern, which could have a positive effect on knee function after TKA. We studied mid-term results of single-radius designed cruciate retaining (CR) TKA.

Materials and Methods: We analyzed the functional improvement and radiological osteolytic pattern after TKA using the single-radius Scorpio CR prosthesis. TKA was performed on 102 knees. The mean follow-up period was 73.8 months. For clinical assessment, the range of motion (ROM), Harris hip score, and functional outcome score were obtained preoperatively and at last follow-up.

Results: The average ROM was $100.2^{\circ}$ preoperatively and $121.7^{\circ}$ at last follow-up. The average knee score was 59.2 points preoperatively and 92.9 points at last follow-up. The average functional outcome score was improved from 51.9 points preoperatively to 85.4 points at last follow-up. Radiolucency was observed in four knees but all were non-progressive lesions smaller than $2 \mathrm{~mm}$.

Conclusions: The clinical outcome of TKA using the single-radius CR prosthesis was good during the mid-term follow-up and the incidence of osteolysis was very rare.
\end{abstract}

Keywords: Knee, Arthroplasty, Cruciate-retaining, Single-radius

\section{Introduction}

The single-radius design of the knee implant has a long patellofemoral moment arm and provides consistent joint stability and articulation through a range of motion. It has recently been suggested as ideal for restoring normal knee kinematics based on some studies that emphasize the importance of the horizontal transepicondylar $\operatorname{axis}^{1,2)}$. The moment arm of the multi-radius prosthesis is shorter than that of the single-radius prosthesis, which causes weakening of extension function ${ }^{3)}$. In contrast, the single-radius prosthesis is designed to have an extended quadri-

Received March 20, 2013; Revised (1st) July 11, 2013; (2nd) August 3, 2013; Accepted August 5, 2013

Correspondence to: Churl Hong Chun, MD

Department of Orthopedic Surgery, Wonkwang University School of

Medicine \& Hospital, 895 Muwang-ro, Iksan 570-974, Korea

Tel: +82-63-859-1363, Fax: +82-63-852-9329

E-mail: cch@wonkwang.ac.kr

This is an Open Access article distributed under the terms of the Creative Commons Attribution Non-Commercial License (http://creativecommons.org/licenses/by-nc/3.0/) which permits unrestricted non-commercial use, distribution, and reproduction in any medium, provided the original work is properly cited. ceps moment arm. The extension mechanism has a significant influence on the stability of the knee joint, gait pattern, and speed, and the increase of the lever of extension mechanism has been reported to reduce the tightness of the quadriceps muscle and patellofemoral compressive forces ${ }^{4,5)}$.

The Scorpio cruciate-retaining (CR) total knee prosthesis (Stryker Orthopaedics, Mahwah, NJ, USA) improves the horizontal axis during flexion-extension of the extension mechanism as a single-radius prosthesis immobilized to the posterior femoral condylar axis. Good clinical outcomes of total knee arthroplasty (TKA) using the Scorpio posterior stabilized (PS) total knee prosthesis (Stryker Orthopaedics) have been reported ${ }^{6-8)}$. However, reports on the use of the Scorpio CR total knee prosthesis are rare.

The aim of this study was to evaluate the radiological and clinical outcomes of TKA using the single-radius Scorpio CR prosthesis.

\section{Materials and Methods}

\section{Study Subjects}

TKA using the Scorpio CR prosthesis was performed in 128 

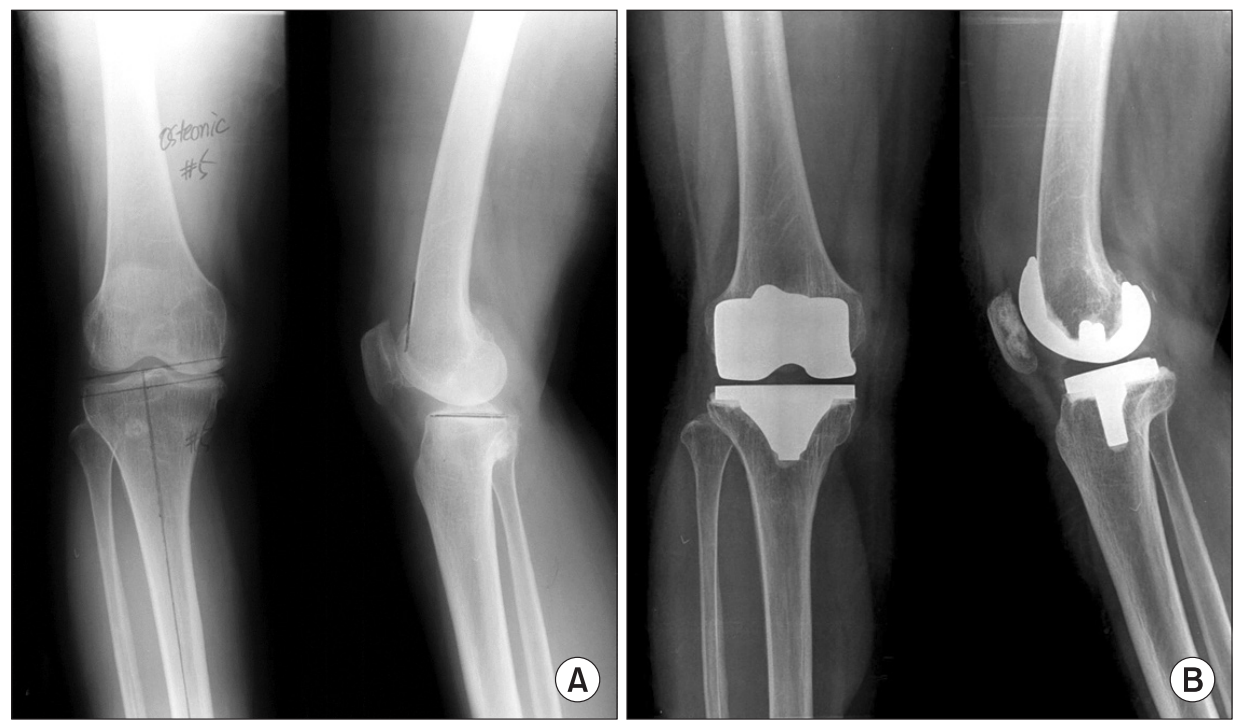

Fig. 1. A 72-year-old female housekeeper underwent total knee arthroplasty (TKA) using a single-radius cruciate retaining knee prosthesis. (A) Preoperative radiograph. (B) At 97 months after TKA, femoral and tibial components did not show any radiolucency.

patients (156 knees) by one senior surgeon (CHC) from August 2000 to November 2004. Excluding 46 patients who were unable to be followed up (unable to contact, 21 patients; moved to other cities, 22 patients; died of medical causes, three patients), 82 patients (102 knees) were enrolled in this study (Fig. 1). The average follow-up period was 73.8 months (range, 60 to 91 months). Among the 46 excluded patients, 13 were male and 69 were female. The average age at the time of surgery was 63.8 years (range, 59 to 79 years). The surgery was performed on the left side in 25 patients and right side in 37 patients, and bilateral in 20 patients. The preoperative diagnosis was degenerative arthritis in 93 knees, rheumatoid arthritis in 6 knees, and traumatic arthritis in 3 knees. Patients with a varus and valgus deformity of more than $15^{\circ}$ and patients with a flexion contracture of more than $30^{\circ}$ were excluded. The patella was resurfaced in 63 knees and retained in 39 knees.

\section{Surgical Methods}

A medial parapatellar approach was used and the Scorpio CR knee prosthesis was implanted in all patients. Bone cutting of the femur was performed using an intramedullary guide at seven degrees valgus and at three degrees of external rotation relative to the posterior condylar axis. Tibial osteotomy was performed using an extramedullary guide with the posterior slope set at five degrees. To retain the posterior cruciate ligament, an osteotomy was performed horizontally up to the posterior cruciate ligament, and subsequently, bones around the posterior cruciate ligament were removed using a rongeur. The balance between the medial and lateral ligaments was examined by inserting an experimental prosthesis. During flexion, if the front of the tibia was lifted and the tibial tray was protruded, the posterior cruciate ligament was considered excessively tense, and accordingly posterior cruciate ligament recession was carefully performed in the tibia area. Patella resurfacing was performed in 63 knees where more than grade III Outerbridge cartilage damage and severe pain were present in the anterior knee prior to surgery ${ }^{9)}$. Patellar alignment was measured with the no thumb technique ${ }^{10}$. A lateral retinacular release was not performed in all knees. Bone cement (Surgical Simplex P; Stryker Orthopaedics) was used for fixation of the femoral, tibial, and patellar prostheses in all knees.

\section{Clinical and Radiological Analysis}

Clinical evaluation was performed using the knee score and functional score of the American Knee Society ${ }^{11}$. The knee score was based on the assessment of pain, joint stability, joint movement range, flexion deformity, articular deformity angle, etc. The functional score was evaluated based on walking and the ability to climb stairways. The extension mechanism of the knee was assessed by asking the patient to stand up from a chair with arms folded across the chest.

Preoperatively, postoperatively and at last follow-up, radiological assessments were performed using standard weight-bearing anteroposterior or long-leg radiographs, supine lateral radiographs, and tangential radiographs of the patella according to the evaluation system of the American Knee Society ${ }^{12}$. The change in the femorotibial angle was measured. With regard to the location of the femoral prosthesis, the valgus angle of the femoral prosthesis $(\alpha)$ and the varus angle of tibial prosthesis $(\beta)$ were measured on the anteroposterior radiographs of the knee. The flexion angle of the femoral prosthesis $(\gamma)$ was measured on lateral radio- 
graphs. To assess the loosening of the knee prosthesis, the tibia was divided to seven areas on the anteroposterior radiographs. The femur was divided to seven areas on the lateral radiographs. Prosthetic loosening was defined as a radiolucency of more than $2 \mathrm{~mm}$. A value lower than 4 points was considered insignificant, 5-9 points was considered as the presence of a lesion with a potential for progression and higher than 10 points as high possibility to fail even in asymptomatic cases.

We used the Kaplan and Meier ${ }^{13)}$ analysis to investigate the survivorship of each implant and the end point was defined as failure with revision for aseptic loosening or instability. For the comparative analysis of statistical association, a paired t-test was performed using the SPSS ver. 12.0 (SPSS Inc., Chicago, IL, USA), and the significance level was set at $\mathrm{p}<0.05$.

\section{Results}

\section{Clinical Results}

On the evaluation of the range of motion of the knee, the average flexion contracture was $14.7^{\circ}$ (range, $8^{\circ}$ to $30^{\circ}$ ) prior to surgery, and $3.2^{\circ}$ (range, $0^{\circ}$ to $5^{\circ}$ ) at the last follow-up. The average maximal flexion was $100.2^{\circ}$ (range, $90^{\circ}$ to $115^{\circ}$ ) prior to surgery and $121.7^{\circ}$ (range, $110^{\circ}$ to $130^{\circ}$ ) at the last follow-up, showing significant improvement $(\mathrm{p}<0.001)$. The average knee score was 59.2 points prior to surgery and 92.9 points at the last follow-up. The average functional score was improved from 51.9 points prior to surgery to 85.4 points at the last follow-up ( $<<0.003)$ (Table 1 ). On the chair-rise test, 72 knees of the patients (70.5\%) were able to rise from a chair without help. Postoperative pain was noted in three of the 63 knees (4.7\%) in the patellar resurfacing group, two of which had a large femoral component. One in 39 knees (2.6\%) in the unresurfaced group developed similar anterior knee pain. There was no case of patellofemoral instability or patellofemoral related stiffness.

\section{Radiological Results}

The average varus-valgus deformity of femur and tibia that was $9.8^{\circ}$ varus prior to surgery was improved to $4.7^{\circ}$ valgus after surgery $(\mathrm{p}<0.002)($ Table 1$)$.

In regard to the results of radiological evaluation, the average postoperative $\alpha$ angle, $\beta$ angle, and $\gamma$ angle were measured as $94^{\circ}$, $91.1^{\circ}$, and $88.8^{\circ}$, respectively. Radiolucency was shown in four knees: in the femoral zone I in one knee; in the femoral zone IV in two knees; and in the tibial zone I in one knee. All were confirmed to be non-progressive lesions smaller than $2 \mathrm{~mm}$.

\section{Complications}

In one knee, infection occurred three weeks after surgery, but it resolved without sequelae after debridement. Deep space infection developed in another knee eight months after surgery, and revision arthroplasty was performed using two-stage techniques. Periprosthetic fractures were observed in three knees (2.9\%): it occurred in the proximal tibia during surgery, and thus fixated by using screws in one knee; it occurred in the distal femur at 14 months after surgery, and thus surgery was performed using a retrograde intramedullary nail in another knee; a patellar fracture and extensive osteolysis around the prosthesis of the knee joint occured simultaneously 68 months after surgery, and thus reimplantation of the prosthesis, reduction for the patellar fracture, and internal fixation were performed in the other knee (Fig. 2).

\section{Survival Rate Analysis}

Revision arthroplasty, defined as the endpoint of the analysis, was performed in one knee due to deep infection and in another knee due to a periprosthetic fracture and extensive osteolysis around the prosthesis. The survival rate at a maximum follow-up of 91 months was $98 \%$.

\section{Discussion}

Kolisek and Barnes ${ }^{7}$ reported that the complication of total

Table 1. Analysis of Clinical Results of Total Knee Arthroplasty

\begin{tabular}{|c|c|c|c|c|c|}
\hline & Preoperative & Postoperative & Mean improvement & t-score & p-value \\
\hline Range of motion $\left({ }^{\circ}\right)$ & $100.24 \pm 6.87$ & $121.68 \pm 6.02$ & $21.44 \pm 8.54$ & 25.33 & $<0.001$ \\
\hline Flexion contracture $\left(^{\circ}\right)$ & $14.72 \pm 3.41$ & $3.21 \pm 2.27$ & $-11.51 \pm 3.34$ & -34.73 & $<0.001$ \\
\hline Knee score & $59.20 \pm 3.43$ & $92.94 \pm 2.71$ & $33.74 \pm 2.83$ & 120.32 & $<0.003$ \\
\hline Functional score & $51.88 \pm 3.65$ & $85.40 \pm 4.38$ & $33.52 \pm 4.83$ & 70.07 & $<0.003$ \\
\hline Femorotibial angle $\left(^{\circ}\right)$ & Varus $9.75 \pm 2.24$ & Valgus $4.66 \pm 1.44$ & $14.41 \pm 2.40$ & 21.36 & $<0.002$ \\
\hline
\end{tabular}

Values are presented as mean \pm standard deviation. 

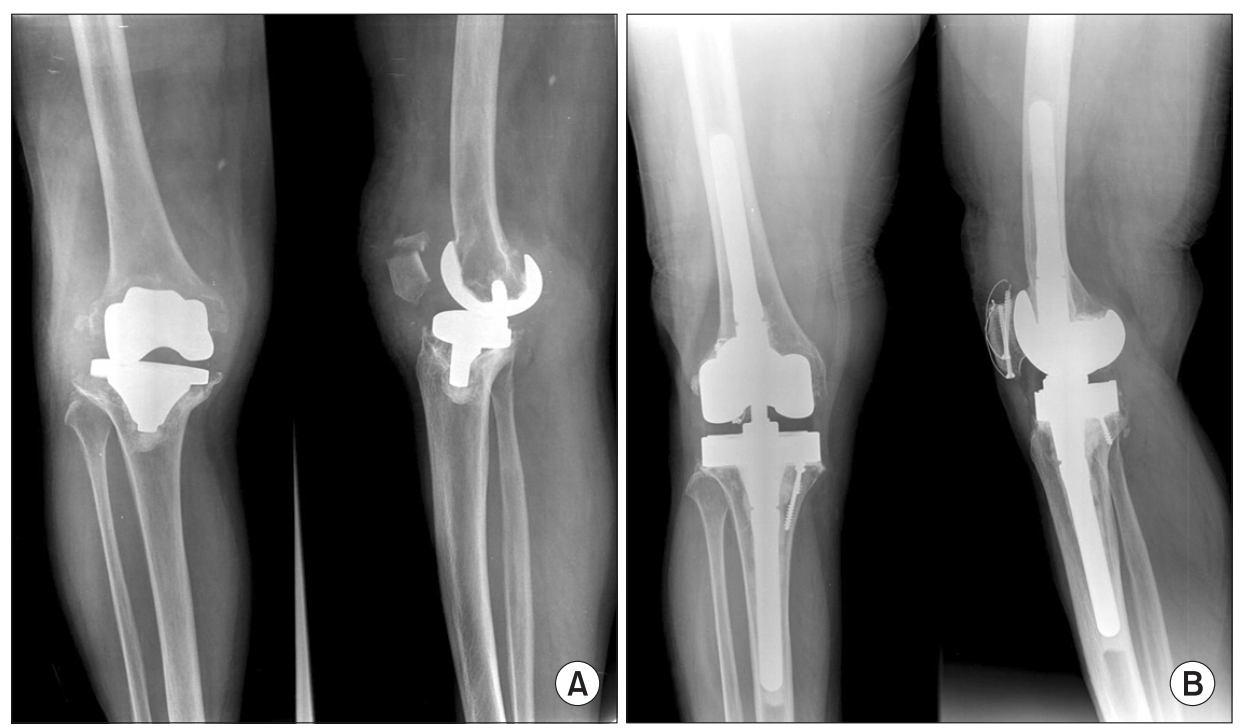

Fig. 2. At 68 months after total knee arthroplasty (TKA), the patient visited our hospital for knee pain after a slip down. (A) The radiograph showed patellar fracture and extensive osteolysis around the prosthesis. (B) A revision TKA was performed using a femoral head allograft for the defect in the medial tibia and fixation was performed with cannulated screws and wiring on patella.

knee arthroplasties using the single-radius Scorpio PS total knee prosthesis was $4.9 \%$ in the follow-up of more than five years. In a study by Mahoney and Kinsey ${ }^{8)}$, the survival rate of the singleradius Scorpio PS knee prosthesis was 95.8\% in the follow-up of 5 to 9.5 years. Abbas and Gunn ${ }^{6}$ reported non-progressive radiolucency was observed in the tibial area in eight knees and in the femoral area in one knee during the average 70 months of followup after TKA using the single-radius Scorpio PS knee prosthesis. In their study, severe osteolysis was found in only one knee and for which revision arthroplasty was performed. In our study, infection occurred in 2 knees (1.9\%) and a periprosthetic fracture in 3 knees (2.9\%), demonstrating superior results to those in other studies. However, the single-radius Scorpio CR knee prosthesis was not different from other total knee prostheses in terms of clinical and radiological results.

The single-radius Scorpio knee prosthesis was designed to have the same diameter of the distal axis and the posterior axis on the sagittal plane, the rotation center during flexion-extension is located $10 \mathrm{~mm}$ more posterior than most conventional knee prostheses, and thus as the moment arm becomes longer, the tension of the femoral quadriceps muscle is reduced. It has been reported that reduction of the tension of the femoral quadriceps muscle reduces pain in the anterior knee, and thus it could improve clinical outcomes and decrease complications associated with erosion and loosening of the knee joint prosthesis ${ }^{3,8,14}$. Kolisek and Barnes ${ }^{7}$ reported that the incidence of pain in the anterior knee was 3\%-5\% in knees with the Scorpio PS type. Abbas and Gunn ${ }^{6}$ reported that in the more than five-year follow-up after knee arthroplasty using the Scorpio PS knee prosthesis, the overall outcome was more than satisfactory in $92.8 \%$ of the patients, but the chair-rise test performed to assess the extension mechanism showed patients who could stand up without any help were low as $58 \%$. In our study, the average Harris hip score was 92.9 points and anterior knee pain was noted in 4 knees (3.9\%) in the followup for a maximum of 91 months, which was not significantly different from other studies. In the chair-rise test, 72 in 102 knees (70.5\%) of the patients could stand up without aid.

Greene and Schurman ${ }^{15)}$ suggested that the function of the femoral quadriceps muscle after TKA is associated not only with the selection of prosthesis but also with patient characteristics, surgical techniques and the provision of rehabilitation. On the other hand, single-radius prostheses require less force of the muscles of extension function, facilitating rapid recovery during rehabilitation $^{3,14)}$. We also believe that it is difficult to improve the function of the femoral quadriceps muscle only with the use of a singleradius prosthesis. However, for Asians in whom sitting and standing up are often required for daily living activities, the increase in the moment arm of the femoral quadriceps muscle would result in rapid recovery of the extensor function. Moreover, the singleradius design reduces loading on the patellofemoral articular surface, contributing to improvement in anterior knee pain. In TKA, whether to retain the posterior cruciate ligament is still highly controversial $^{16,17)}$. It has been reported that the early failure of PS knee prosthesis is abundant due to osteolysis caused by backside wear and tibial post wear ${ }^{18,19)}$. However, numerous investigators have reported that clinical and radiological results of total knee arthroplasties using the CR type and PS type prostheses are not greatly different ${ }^{5,20-22)}$. In cases of the $\mathrm{CR}$ type prosthesis, if the dynamics of the knee joint is disrupted due to e7xcessive tightness or laxity of the posterior cruciate ligament, it may mediate adverse 
effects on knee function and the long-term follow-up results. In addition, it allows the femur to roll during flexion, improving the effect of the extension mechanism, and reduces shearing force of the tibial prosthesis and the tibial contact surface by distributing and transferring shearing force loaded onto the joint, resulting in reduced incidence of polyethylene wear ${ }^{23-25)}$. Hall et al. ${ }^{26)}$ reported that retention of the posterior cruciate ligament is a more important mediating factor on the extension mechanism than the design of total knee prosthesis. Because of the improvement of the moment arm of the femoral quadriceps muscle of the single-radius prosthesis and the retention of the posterior cruciate ligament, enhanced improvement of the extension mechanism was noted and complications associated with the patellofemoral articular surface decreased, which led to increased patient satisfaction.

The limitation of this study is that no comparison was made between the single-radius TKA and the multiple radius TKA.

\section{Conclusions}

TKA using the single-radius CR prosthesis increased the moment arm of the femoral quadriceps and thus improved the function of the muscle. The rate of osteolysis was low and patient satisfaction was high.

\section{Conflict of Interest}

No potential conflict of interest relevant to this article was reported.

\section{Acknowledgments}

This article was funded by Wonkwang University in 2013.

\section{References}

1. Churchill DL, Incavo SJ, Johnson CC, Beynnon BD. The transepicondylar axis approximates the optimal flexion axis of the knee. Clin Orthop Relat Res. 1998;(356):111-8.

2. Hollister AM, Jatana S, Singh AK, Sullivan WW, Lupichuk AG. The axes of rotation of the knee. Clin Orthop Relat Res. 1993;(290):259-68.

3. D'Lima DD, Poole C, Chadha H, Hermida JC, Mahar A, Colwell CW Jr. Quadriceps moment arm and quadriceps forces after total knee arthroplasty. Clin Orthop Relat Res. 2001;(392):213-20.

4. Barrack RL, Wolfe MW. Patellar resurfacing in total knee arthroplasty. J Am Acad Orthop Surg. 2000;8:75-82.

5. Healy WL, Wasilewski SA, Takei R, Oberlander M. Patellofemoral complications following total knee arthroplasty: correlation with implant design and patient risk factors. J Arthroplasty. 1995;10:197-201.

6. Abbas D, Gunn RS. Medium-term results of the Scorpio total knee replacement. Knee. 2006;13:307-11.

7. Kolisek FR, Barnes CL. Scorpio posterior-stabilized knee system: 5-year clinical and functional results. J Arthroplasty. 2006;21:1187-92.

8. Mahoney OM, Kinsey TL. 5- to 9-year survivorship of single-radius, posterior-stabilized TKA. Clin Orthop Relat Res. 2008;466:436-42.

9. Outerbridge RE. The etiology of chondromalacia patellae: 1961. Clin Orthop Relat Res. 2001;(389):5-8.

10. Scott WN, Insall JN. Insall \& Scott surgery of the knee. 5th ed. Philadelphia, PA: Elsevier/Churchill Livingstone; 2012. p1071-2.

11. Insall JN, Dorr LD, Scott RD, Scott WN. Rationale of the Knee Society clinical rating system. Clin Orthop Relat Res. 1989;(248):13-4.

12. Ewald FC. The Knee Society total knee arthroplasty roentgenographic evaluation and scoring system. Clin Orthop Relat Res. 1989;(248):9-12.

13. Kaplan EL, Meier P. Nonparametric estimation from incomplete observations. Am Stat Assoc 1958;53:457-81.

14. Wang H, Simpson KJ, Chamnongkich S, Kinsey T, Mahoney $\mathrm{OM}$. A biomechanical comparison between the single-axis and multi-axis total knee arthroplasty systems for the standto-sit movement. Clin Biomech (Bristol, Avon). 2005;20:42833.

15. Greene KA, Schurman JR 2nd. Quadriceps muscle function in primary total knee arthroplasty. J Arthroplasty. 2008;23(7 Suppl):15-9.

16. Poss R, Thornhill TS, Ewald FC, Thomas WH, Batte NJ, Sledge CB. Factors influencing the incidence and outcome of infection following total joint arthroplasty. Clin Orthop Relat Res. 1984;(182):117-26.

17. Ranawat CS, Hansraj KK. Effect of posterior cruciate sacrificing on durability of the cement-bone interface: a nine-year survivorship study of 100 total condylar knee arthroplasties. Clin Exp Rheumatol. 1989;7 Suppl 3:S149-52.

18. Puloski SK, McCalden RW, MacDonald SJ, Rorabeck CH, Bourne RB. Tibial post wear in posterior stabilized total knee arthroplasty. An unrecognized source of polyethylene debris. J Bone Joint Surg Am. 2001;83:390-7. 
19. Wasielewski RC, Parks N, Williams I, Surprenant H, Collier JP, Engh G. Tibial insert undersurface as a contributing source of polyethylene wear debris. Clin Orthop Relat Res. 1997;(345):53-9.

20. Becker MW, Insall JN, Faris PM. Bilateral total knee arthroplasty: one cruciate retaining and one cruciate substituting. Clin Orthop Relat Res. 1991;(271):122-4.

21. Dennis DA, Komistek RD, Stiehl JB, Walker SA, Dennis KN. Range of motion after total knee arthroplasty: the effect of implant design and weight-bearing conditions. J Arthroplasty. 1998;13:748-52.

22. Dorr LD, Ochsner JL, Gronley J, Perry J. Functional comparison of posterior cruciate-retained versus cruciatesacrificed total knee arthroplasty. Clin Orthop Relat Res.
1988;(236):36-43.

23. Andriacchi TP, Galante JO. Retention of the posterior cruciate in total knee arthroplasty. J Arthroplasty. 1988;3 Suppl:S13-9.

24. Scott RD, Volatile TB. Twelve years' experience with posterior cruciate-retaining total knee arthroplasty. Clin Orthop Relat Res. 1986;(205):100-7.

25. Sorger JI, Federle D, Kirk PG, Grood E, Cochran J, Levy M. The posterior cruciate ligament in total knee arthroplasty. J Arthroplasty. 1997;12:869-79.

26. Hall J, Copp SN, Adelson WS, D’Lima DD, Colwell CW Jr. Extensor mechanism function in single-radius vs multiradius femoral components for total knee arthroplasty. J Arthroplasty. 2008;23:216-9. 